\title{
O DIREITO À CIDAdE COMO PRÁticA dE RESISTÊnCIA A POLíticas de GENTRIFICAÇÃO E DE REMOÇÕES FORÇADAS: O CASO DA COMUNIDADE METRÔ- MANGUEIRA (RIO DE JANEIRO)
}

\section{THE RIGHT TO THE CITY AS PRACTICE OF RESISTANCE TO POLICIES OF GENTRIFICATION AND COMPELLED REMOVALS: THE CASE OF METRÔ-MANGUEIRA COMMUNITY (RIO DE JANEIRO)}

Enzo Bello ${ }^{1}$ Marcelo Queiroz ${ }^{2}$

\begin{abstract}
Resumo
O presente artigo almeja discutir o direito à cidade como prática de resistência dos moradores da Comunidade Metrô-Mangueira às políticas de gentrificação e de remoções forçadas na cidade do Rio de Janeiro, no contexto dos megaeventos esportivos internacionais. Analisa os conflitos jurídicos e sociais para garantia do direito à cidade dos cidadãos da comunidade, e suas estratégias de resistência às políticas públicas da prefeitura municipal. Estas voltadas à apropriação do território para promoção de obras de infraestrutura urbana com a iniciativa privada. A pesquisa tem natureza qualitativa e perfil jurídico-sociológico, adota raciocínio dedutivo-indutivo e tem como referencial teórico-metodológico a teoria crítica da sociedade capitalista. Utiliza as técnicas de pesquisa de revisão bibliográfica, análise documental e estudo de caso. As fontes primárias são dados extraídos de entrevistas com moradores, comerciantes e trabalhadores da Comunidade Metrô-Mangueira. As fontes secundárias são livros, artigos e documentos.
\end{abstract}

Palavras-chave: Direito à cidade; Direito de resistência; Gentrificação; Remoções forçadas; Comunidade Metrô-Mangueira.

\begin{abstract}
This paper aims to discuss the right to the city as practice os resistance of the residents from Metrô-Mangueira Community to the policies of gentrification and compelled removals at the city of Rio de Janeiro, in the context of the international mega sportive events. It analyses the legal and social conflicts to the guaranty of the right to the city of the community residents and their resistance strategies to the public policies of the city council. These aimed to territory appropriation to the accomplishment of urban infrastructure constructions with private

\footnotetext{
${ }^{1}$ Doutor em Direito pela Universidade do Estado do Rio de Janeiro (UERJ). Estágio de Pós-Doutorado em Direito pela Universidade do Vale do Rio dos Sinos (UNISINOS). Estágio de Pós-doutorado em Serviço Social pela Universidade Federal do Rio de Janeiro (UFRJ). Professor Adjunto IV da Faculdade de Direito e do Programa de Pós-Graduação em Direito Constitucional da Universidade Federal Fluminense (UFF). Coordenador do Núcleo de Estudos e Projetos Habitacionais e Urbanos (NEPHU) - UFF. Editor-chefe da Revista Culturas Jurídicas (www.culturasjuridicas.uff.br). Professor do Programa de Pós-graduação em Direito da Universidade Estácio de Sá (UNESA). Consultor da Coordenação de Aperfeiçoamento de Pessoal em Nível Superior (CAPES). E-mail: enzobello@gmail.com

${ }^{2}$ Doutorando em Direito da Cidade pelo PPGD/UERJ. Mestre em Direito Constitucional pelo PPGDC/UFF. Especialista em Direito pela UERJ, UFF e FGV. E-mail: marceloqueiroz@id.uff.br
} 
enterprises. The research has qualitative nature and legal-sociological profile, adopts deductiveinductive reasoning and has as theoretical-methodological referential the critical theory of the capitalist society. It uses the research techniques of bibliographic review, documentary analysis and case study. The primary sources are data extracted from interviews with residents, traders and workers of the Metrô-Mangueira Community. The secondary resources are books, papers and documents.

Keywords: Right to the city; Right of resistance; Gentrification; Compelled removals; MetrôMangueira Community.

\section{INTRODUÇÃO}

O Estado tem atuado como operador de violações do direito à cidade, a partir da integração com os interesses privados e corporativos e por meio de uma política urbana de perfil econômico neoliberal ${ }^{3}$. O aparato estatal favorece o capital corporativo e o grande empresariado, na moldagem do processo de urbanização, promovendo a cidade como espaço ótimo para grandes negócios e destino atraente para turistas (HARVEY, 2008).

Essa realidade torna-se ainda mais grave quando se reflete sobre a realidade em que 0 Brasil foi inserido, em decorrência das decisões de sediar megaeventos esportivos internacionais, que ensejaram reflexões sobre suas implicações e o legado que ficaria para a população, sobretudo a mais pobre e vulnerável. Diante da nomeação do Brasil para receber uma sequência de eventos e da cidade do Rio de Janeiro para ser uma das cidades-sede da Copa do Mundo de 2014 e a sede dos Jogos Olímpicos Rio 2016, e com a coalização das três esferas federativas de poder, criou-se na população fluminense a expectativa de que problemas urbanos recorrentes - transporte público, saúde, saneamento básico etc. - seriam enfrentados por meio de políticas públicas de melhorias à cidade.

\footnotetext{
${ }^{3}$ O termo "neoliberalismo" se caracteriza como categoria teórica. Sobre as suas origens, com amparo em David Harvey (2005, p. 07 e 120 e ss.), assim afirma Bello (2007, p. 52): “(...) as experiências precursoras de liberalização ocorreram no Chile e na China, respectivamente, a partir de 1973 e 1978. Com a ditadura de Augusto Pinochet, que derrubou o governo do socialista Salvador Allende, o Chile funcionou como laboratório de experiências para a aplicação das teorias trazidas pelos denominados 'Chicago boys'. Com a desregulamentação do mercado, a privatização de importantes setores como a seguridade social e a abertura dos recursos naturais (exceto o cobre) para exploração por empresas internacionais, o Chile apresentou grandes taxas de crescimento econômico e serviu de parâmetro para futuras experiências de liberalização forçada, tais como a do Iraque. Por seu turno, em momento simultâneo à adoção da 'solução neoliberal' nos EUA e na Grã-Bretanha, a China implementou um amplo programa de reforma econômica, que transformou o país no mais novo player do mercado econômico mundial e viabilizou a construção de um sistema peculiar de economia de mercado. Capitaneado por Deng Xiaoping, esse projeto envolveu uma mistura de elementos neoliberais com um controle autoritário e centralizado da economia por parte do estado, tendo sido pautado em um estímulo à competição entre as empresas estatais e as novas organizações do mercado, assim como pela modernização articulada entre quatro setores de base: a agricultura, a indústria, a educação e a ciência".
} 
Todavia, o poder público colocou em pauta políticas públicas de urbanização para áreas definidas como prioritárias, segundo a perspectiva de análise da FIFA e do Comitê Olímpico Internacional (COI), principalmente quanto à mobilidade urbana e à segurança pública. Tal decisão afetou comunidades carentes que, de longa data, viviam em áreas próximas aos palcos dos referidos megaeventos, historicamente negligenciadas pelos entes públicos.

Sob esse ângulo de análise, a ineficiência das políticas públicas indica a negação do direito à cidade aos moradores dessas comunidades. Uma delas é a Comunidade do MetrôMangueira, que chamou a atenção do aparato estatal por sua proximidade com o Estádio Jornalista Mário Filho ("Estádio do Maracanã").

Com pretextos diversos, acompanhados do verniz de implementação de políticas públicas, os entes públicos envolvidos, alinhados com grandes empreiteiras, transformaram o município em um grande "canteiro de obras", pondo em prática uma política higienista, através de remoções forçadas em duas regiões olímpicas. Exemplos eloquentes do predomínio dos interesses econômicos das grandes empresas sobre os interesses sociais dos cidadãos situam-se na região da Barra da Tijuca, na Vila Autódromo, e na região do Maracanã, que compreende a Comunidade Metrô-Mangueira.

Por estar localizada em área de elevada valorização imobiliária, a Vila Autódromo sofria ameaça de remoção há mais tempo, desde a década de 1990. Na Comunidade MetrôMangueira o processo de remoção também foi extremamente agressivo, marcado pela falta de transparência e diálogo por parte do governo do município do Rio de Janeiro, à época comandado pelo então Partido do Movimento Democrático Brasileiro (PMDB) - atual MDB -, que também comandava o governo do Estado, todos em sintonia com o governo federal, que tinha como vice-presidente um integrante da legenda. Momentos de coercibilidade exacerbada tornaram-se rotineiros para os moradores da Comunidade Metrô-Mangueira, que ganharam visibilidade por parte da imprensa nacional e estrangeira.

O presente artigo toma como ponto de partida a contradição entre o direito à cidade como espécie de direitos humanos e a atuação estatal na desapropriação de moradias ou pequenos comércios na Comunidade Metrô-Mangueira, em benefício dos interesses de grandes empreiteiras sob a justificativa de necessidade das obras destinadas aos megaeventos (Copa do Mundo de 2014 e dos Jogos Olímpicos Rio 2016) que viriam a ocorrer na cidade do Rio de Janeiro.

O texto está estruturado numa sequência de tópicos que apresentam a empiria pesquisada, a metodologia e a teoria adotadas, para pavimentar o caminho para reflexões 
sobre a dinâmica do direito de resistência dos moradores da comunidade Metrô-Mangueira. São confrontados dois conceitos principais, capital e direitos humanos, na vertente do direito à cidade (LEFEBVRE, 1969; HARVEY, 2010) como direito individual e coletivo que abrange, entre outros, o direito à moradia, o direito à propriedade e o direito de resistência.

A pesquisa tem natureza qualitativa e perfil jurídico-sociológico, adota raciocínio dedutivo-indutivo e tem como referencial teórico-metodológico a teoria crítica da sociedade capitalista (HORKHEIMER, 1983). Utiliza as técnicas de pesquisa de entrevista, revisão bibliográfica, análise documental e estudo de caso. As fontes primárias são dados extraídos de entrevistas com moradores, comerciantes e trabalhadores da Comunidade Metrô-Mangueira, como forma de se evidenciar a realidade social e de se dar visibilidade a sujeitos subalternizados. As fontes secundárias são livros, artigos e documentos.

\section{EMPIRIA: PROCEDIMENTOS METODOLÓGICOS E DESCRIÇÃO DO CAMPO DE INVESTIGAÇÃO}

\section{Procedimentos metodológicos adotados na coleta dos dados}

Um dos aspectos mais marcantes que caracteriza o homem contemporâneo é sua capacidade de desenvolver uma postura crítica diante dos desafios com que se defronta no cotidiano, impostos pela convivência numa sociedade cuja escala de valores se funda na excessiva competitividade. Marshall Berman (2005, p. 15) exprime com muita propriedade o ambiente característico da contemporaneidade:

Ser moderno é encontrar-se em um ambiente que promete aventura, poder, alegria, crescimento, autotransformação e transformação das coisas em redor - mas ao mesmo tempo ameaça destruir tudo que temos, tudo o que sabemos, tudo o que somos. [...]. Ser moderno é fazer parte de um universo no qual, como disse Marx, "tudo que é sólido desmancha no ar".

Diante de um quadro de múltiplas representatividades como o delineado por Berman (2005), o sujeito contemporâneo muitas vezes se vê enredado nas injunções da modernidade, sendo avassalado pela dinâmica das transformações. Daí a necessidade de estar preparado para lidar com o ambiente que leva à fragmentação de "identidades abertas, contraditórias, inacabadas, fragmentadas" do sujeito na atualidade (HALL, 2005, p. 46).

Tal fragmentação imposta aos indivíduos é levada em conta quando se constrói, neste estudo, o perfil dos membros da Comunidade Metrô-Mangueira, diante da situação à qual 
foram submetidos com o processo de remoção implementado pela Prefeitura, no sentido de desmantelar sua área de convivência e de ceder o espaço para a realização das obras desejadas para os Jogos Olímpicos de 2016. Vale lembrar que, na iminência da realização da Copa do Mundo de 2014, a comunidade já havia passado por um processo semelhante, exigindo uma resistência inaudita dos moradores, para evitarem a mudança impositiva, conforme reportado em depoimento do RioWatch (2017):

Em outubro/novembro de 2010, a Prefeitura entrou intimidando moradores dizendo que tinham que sair de lá. Motivo: "limpar" a área para a Copa. 107 não resistiram e foram nessa primeira leva, para o Condomínio Varese do Minha Casa Minha Vida, em Cosmos $(70 \mathrm{~km}$ de distância da comunidade, ou 2 horas de trem). Os que ficaram resistiram com ajuda da Defensoria do Estado do Rio e Pastoral das Favelas.

Enquanto isso, a Prefeitura entrou na comunidade e a marretada derrubou as casas dos primeiros 107 que saíram, deixando buracos enormes na comunidade que, desde então, atraem usuários de drogas, prostituição, focos de dengue e assaltos.

Por conta dos problemas atraídos pela demolição das casas, os moradores toparam ser realocados em sequência, mas com ajuda da Defensoria insistiram que só sairiam se fosse para um condomínio próximo. Com isso, uma segunda leva de por volta 300 famílias foram realocadas para o Condomínio Mangueira I, do Minha Casa Minha Vida, construído na mesma região, dentro da Mangueira, no início de 2011.

Em virtude destas postulações que deixam uma impressão de déjà vu e nas quais se repete semelhante situação já verificada em 2010, foi realizada pesquisa empírica, mediante a técnica de estudo de caso. O objetivo foi investigar, junto a moradores, comerciantes e trabalhadores com iniciativas de empreendedorismo na Comunidade Metrô-Mangueira, suas percepções e opiniões sobre a ação da Prefeitura nesta onda de remoções e sobre seus impactos na "clientela", além de demonstrar as estratégias adotadas para se defenderem da ação governamental.

A coleta de dados foi realizada no período de 13 a 20 de fevereiro de 2017, por meio de questionários preenchidos pelos próprios entrevistados ${ }^{4}$. Foram formuladas 27 questões objetivas, com uma linguagem acessível aos entrevistados. Dez foram selecionadas por critérios representatividade em meio ao universo pesquisado.

Com o intuito de futura divulgação da pesquisa e no sentido de preservar a identidade dos entrevistados, foi formulada uma questão com a qual se procurou definir, com eles, o grau de sigilo a ser adotado durante a publicação de suas opiniões. Seis entrevistados autorizaram constar seus nomes próprios na pesquisa e em futuros livro e artigos sobre esta experiência; um

\footnotetext{
${ }^{4}$ Os entrevistados foram escolhidos pelo grau de representatividade que possuíam junto à comunidade, alguns deles ocupando status de líderes comunitários.
} 
autorizou que seu nome constasse apenas na pesquisa; três preferiram que se utilizassem apelidos quando se referisse a eles. Como a proposta foi de realizar uma pesquisa qualitativa e não houve autorização de todos os entrevistados para que fossem mencionados seus nomes, decidiu-se por não revelá-los durante a consolidação dos dados. As questões abrangem as seguintes áreas de interesse da pesquisa: moradia e implantação do comércio na Comunidade Metrô-Mangueira; tipo de comércio, relação de propriedade com o imóvel utilizado para a atividade comercial e sua importância para o sustento familiar; percepção sobre as atividades da Prefeitura para implementar a remoção; e perspectivas de solução para o futuro das atividades comerciais na comunidade.

Com base no panorama descortinado acima, adiante serão reproduzidos, de maneira sumária, os dados consolidados durante a pesquisa, além de ser realizada análise crítica a respeito do que as informações obtidas representam no escopo do presente artigo.

\section{DESCRIÇÃO DO CAMPO DE INVESTIGAÇÃO}

A Comunidade Metrô-Mangueira está localizada na cidade do Rio de Janeiro, a 500 metros do Complexo Esportivo do Maracanã, e chegou a reunir 700 famílias (RIOONWATCH, 2017).

O entorno do estádio, palco importante para a Copa do Mundo de 2014 e os Jogos Olímpicos de 2016, recebeu atenção especial do poder público, dos empreiteiros privados de obras públicas e da mídia. Esta importância se deveu, entre outros motivos, à espetacularidade que tais megaeventos representavam, em nível planetário, como expressão do progresso brasileiro. Na visão desses atores cabia àquela área aparecer nos registros midiáticos de modo coerente com o padrão estético do monumental estádio de futebol, considerado um dos cartões postais cariocas mais visitados pelos turistas.

Num magistral trabalho de pesquisa, Lucas Faulhaber e Lena Azevedo publicaram, em 2015, o livro SMH 2016: remoções no Rio de Janeiro Olímpico, no qual relatam com fidelidade as estratégias da Prefeitura da Cidade do Rio de Janeiro para ensejar o afastamento dos moradores das áreas de interesse do capital, a fim de facilitar a especulação imobiliária nestes locais. Com base nas informações registradas pela pesquisa, toma-se conhecimento de que os moradores da Comunidade Metrô-Mangueira sofreram sucessivas ondas de intimidação para que saíssem do local. 
Pedro D’Angelo da Costa e Luiz Eduardo de Vasconcellos Figueira reproduzem o relato de um morador, que denominam de Fausto, sobre os caminhos da resistência articulada na comunidade:

Por volta de um mês após o primeiro contato entre os agentes da Prefeitura e os residentes do Metrô-Mangueira, os moradores foram novamente surpreendidos com a chegada repentina de agentes da Prefeitura na favela. Segundo relatos colhidos, os agentes chegaram à comunidade oferecendo unidades habitacionais em Cosmos, e aqueles que aceitavam, já saíam de suas casas no mesmo momento, com seus pertences em um caminhão de mudança. Fausto conta que esse era um momento de muita tensão entre os moradores, já que alguns aceitavam a mudança e outros insistiam para que ninguém saísse do local; nesse dia, por volta de 60 famílias se mudaram da favela. Alguns moradores tinham uma condição financeira extremamente precária, viviam em casas de madeira e lona, e, ao receber a proposta de um apartamento, aceitaram de imediato. Porém, Fausto argumenta que isso enfraquece a comunidade, que fica menor e mais frágil. Após a posse da última presidente da Associação, poucas famílias aceitaram o imóvel em Cosmos, e então começou a organizar-se a resistência dos moradores, que tinham como pauta a permanência no local ou o reassentamento em local próximo. A reorganização da Associação proporcionou maior proteção aos moradores, garantiu acesso à informação e fez com que os moradores se sentissem mais seguros quanto aos seus direitos [...] (COSTA; FIGUEIRA, 2016, p. 209).

É o caso também do depoimento dramático da cidadã cearense Francileide da Costa

Souza, 45 anos, ao narrar as circunstâncias da primeira investida da Prefeitura para tentar a remoção:

Dia 26 de julho de 2010, a prefeitura chegou na nossa comunidade com muitos carros, assistentes sociais entrando nas casas, filmando e pichando as residências com aquele SMH. Eu estava trabalhando - na época, em Copacabana - e minha filha me ligou, pedindo que eu viesse. Quando cheguei, as pessoas não estavam entendendo o que estava acontecendo. Porque eles faziam tudo isso, mas não diziam para o que era. A gente já imaginava, quando teve a comemoração da Copa do Mundo, que o Brasil tinha sido escolhido, que isso podia acontecer. A gente perguntava se era por causa da Copa e eles negavam e falavam que era programa social. Depois de duas semanas é que viemos saber que era para remoção (SOUZA apud FAULHABER; AZEVEDO, 2015, p. 98).

Com o depoimento da moradora, percebe-se a tática da Prefeitura em usar intempestivamente o elemento surpresa, a fim de que os moradores não pudessem esboçar defesa ou resistência, assinalando as casas condenadas e dando curtíssimo prazo para eles se preparem para a remoção. Nesta primeira investida, a Prefeitura conseguiu retirar 107 moradores, que foram reassentados, sob os auspícios do programa Minha Casa Minha Vida, no Condomínio Varese, no bairro de Cosmos, que fica a $70 \mathrm{~km}$ de distância da comunidade. A partir 
da saída desta primeira leva de moradores, a Prefeitura contratou operários para demolir as casas desocupadas, criando um clima de incerteza para os remanescentes. Foi quando eles decidiram procurar a Defensoria Pública e a Pastoral das Favelas, a fim de conseguirem ajuda para o resguardo de seus direitos (RIOONWATCH, 2017; FAULHABER; AZEVEDO, 2015, p. 99).

O Núcleo de Terras e Habitação (NUTH) da Defensoria Pública do Estado do Rio de Janeiro contribuiu para incentivar a resistência dos moradores da comunidade. Foi a ação conjunta do NUTH e da comunidade que viabilizou a abertura de canais de diálogo com a Prefeitura e a oferta de alternativas habitacionais menos danosas à população. Complementarmente, os moradores passaram a conhecer melhor os seus direitos; este processo de resistência e luta pela moradia modificou a visão de mundo dessas pessoas (MEIRELES, 2018).

Por mais que isso não seja suficiente para transformar completamente a estrutura da sociedade, Meireles (2018) entende que toda forma de deixar em evidência as contradições da realidade e ajudar na construção da consciência política e de luta por direitos da classe trabalhadora pode ser considerada um avanço rumo à construção de uma sociedade mais justa e igualitária. Por esta razão, o período em que o NUTH atuou na Comunidade Metrô-Mangueira representou um uso político e transformador da tutela coletiva prevista no Direito Processual Civil.

Com a participação da Defensoria Pública e da Igreja Católica, os moradores resistentes ganharam novo fôlego e passaram a exigir da Secretaria Municipal de Habitação (SMH) solução mais viável para a questão, como o reassentamento mais próximo à comunidade, pois muitos já tinham atividades profissionais na região, as crianças estavam em meio a seus cursos nas escolas do bairro, além de outros vínculos com o local.

Nesse ínterim, Francileide da Costa Souza, em função da liderança demonstrada durante as negociações com a Prefeitura, veio a ocupar a presidência da Associação de Moradores, pois os dois outros dirigentes haviam sido cooptados pela Prefeitura e, por isso, foram destituídos dos seus cargos. Ela explica como ocorreram penosamente as negociações:

Fizemos muitas reuniões e pedimos para que as pessoas não abandonassem a comunidade, que tivessem coragem pra lutar. Com isso, a gente não dormia. Eu tive que sair do meu trabalho. Aí, minhas colegas ficavam na comunidade, enquanto eu ia para os órgãos, abrindo processo para ver se a gente conseguia não sair. Mas o prefeito começou a mudar todo mundo dos departamentos, na Defensoria Pública. Quando fui falar com o Eduardo Paes, argumentei que tinha gente na Mangueira morando em área de risco e que nossa comunidade não precisava sair, porque não estava em área de risco. Nunca vou esquecer o que ele falou: disse que a 
gente ia sair por que ele queria a comunidade limpa (SOUZA apud FAULHABER; AZEVEDO, 2015, p. 99).

Como resultado positivo desta luta foram construídos os condomínios Mangueira I e Mangueira II, a apenas $1 \mathrm{~km}$ da área em vias de remoção. Porém, as 300 famílias que foram para Mangueira I reclamaram enfaticamente das condições de habitabilidade do condomínio, com diversos problemas na construção. Também as 202 famílias que permaneceram na comunidade aguardando a finalização do condomínio Mangueira II, que só viria acontecer em 2012, ficaram submetidas a péssimas condições de habitação, morando entre os escombros da demolição, como relata ainda Francileide da Costa Souza:

Eles demoliam e deixavam os entulhos. Eu chegava do curso em minha casa às 22 horas. Na comunidade já não tinha uma boa iluminação. Meu filho e meu marido tinham que me buscar. Eu tinha medo dos ratos, de tanto entulho que a prefeitura deixou. Eram ratos horríveis. A prefeitura faz a coisa que é pra maltratar quem resiste. Ela brinca com os nervos e o psicológico da gente (SOUZA apud FAULHABER; AZEVEDO, 2015, p. 100).

Após a mudança do restante dos moradores da comunidade para Mangueira II e 0 bairro não oficial de Triagem, Francileide explica ter ocorrido o seguinte:

Com isso, o que restou foi só o comércio. Este ano [2014], completam-se quatro anos de luta e agente está brigando agora pelos comerciantes, para que eles [a prefeitura] cumpram a palavra do polo automotivo. Nós tínhamos 126 comércios. Só indenizaram nove. Falta o restante. Estamos lutando para que pelo menos o comércio continue no local (SOUZA apud FAULHABER; AZEVEDO, 2015, p. 100).

O depoimento da moradora apresenta com tintas fortes o sintomático descaso do poder público no tratamento desumano das pessoas que experimentam o processo de remoção. Com esta atitude descabida força-se o conflito generalizado da comunidade versus as forças policiais, que, por sua vez, durante as incursões se valem de "estratégias" mais duras de "convencimento" como o uso de bombas de efeito moral, spray de pimenta, balas de borracha e cassetetes, na repressão desmesurada às manifestações de desagrado organizadas pelos moradores.

As remoções feitas na Comunidade Metrô-Mangueira não só foram feitas para servir aos interesses do capital (HARVEY, 2015) como também se pautaram por violência e perversidade.

As remoções impostas pelo poder público aos moradores e comerciantes geraram desterritorialização, com um desenraizamento das práticas socioespaciais ali impressas. As famílias removidas para o bairro de Cosmos, assim como as famílias que foram para os conjuntos habitacionais Mangueira I e II, gradualmente reconstroem suas redes de 
sociabilidade, buscando novas táticas de sobrevivência, num processo muito longo, com muitos percalços e com um custo pessoal, afetivo e econômico muito elevado.

\section{TEORIA: DIREITO À CIDADE, PROTEÇÃO AO DIREITO CONSTITUCIONAL DE MORADIA/PROPRIEDADE E DIREITO DE RESISTÊNCIA}

Quando o assunto é resistência, o primeiro passo é distinguir revolução de revolta. A revolta é obra espontânea e de duração limitada, ao contrário da revolução, que pode não ser espontânea, além da imprevisibilidade de sua extensão temporal, sua força e sua violência fundante, tornando compreensível a reação do Estado: mero instinto de sobrevivência. Segundo Costas Douzinas (2013, p. 98), a resistência é tanto fato como direito, em que "a desobediência nega, e a resistência cria". A desobediência não é ilegal ou anômica, mas uma resposta cívica para a anomia induzida pelo governo, em que o dissenso mantém a promessa do nomos e do dike vivos, ainda que revele a desintegração do ethos e seus elementos, ética e moral, e não se possa negar a sua própria violência na (des)construção do sujeito.

Frente às desenfreadas remoções de moradores sem planejamento e oitiva da Comunidade Metrô-Mangueira, surgiram iniciativas individuais e coletivas de resistência. Apesar da suposta legalidade no agir do Poder Executivo municipal, os cidadãos que ali residem ou trabalham também possuem arcabouços e instrumentos jurídicos que legitimam a reação em não saírem (direito à moradia, direito à propriedade, direito de resistência e direito à cidade). Aqui é importante discutir o uso insurgente do direito legado pelas iniciativas de assessoria jurídica popular e das quais se servem as comunidades carentes.

Logo, o direito insurgente consubstancia-se em tática transitória de uso das relações sociais e jurídicas em um percurso que vai da forma jurídica até sua negação. Transpondo este raciocínio para o contexto das comunidades do Rio de Janeiro que sofreram as remoções forçadas, o direito insurgente pode ser compreendido como a forma de as pessoas carentes usarem o direito em organizações populares como uma alternativa à prática jurídica vigente e como forma de se reapropriarem do poder normativo, fazendo surgir um direito objetivo próprio nas comunidades, o que Ribas e Pazzelo (2015) denominam de direito insurgente. Segundo os autores, "O (des)uso tático e estratégico do direito é uma resposta à urgência de uma crítica que possa ligar os pontos de táticas do uso combativo, relido, assimétrico, dual e negativo do direito; com uma estratégia insurgente revolucionária" (RIBAS; PAZZELO, 2015, p. 156). 
O direito pode servir a fins políticos; logo, a insurgência pode influenciar diretamente na sua extinção, modificação e criação.

A resistência é viva e permanente. Um dos maiores aprendizados de quem atua no campo das disputas fundiárias é entender como os moradores ameaçados se articulam para evitar os despejos, utilizando e inventando, de forma inteligente e sensível, uma série de meios e recursos sociais, culturais, midiáticos, técnicos e jurídicos. Sem essa luta, que é diária, haveriam cifras ainda maiores de violações e despejos.

Enzo Bello (2013) afirma que os novos movimentos sociais viabilizaram a renovação do conceito e prática da cidadania. Assim, as estratégias de resistência dos cidadãos e comunidades atingidos - como a mobilização coletiva e a articulação com movimentos populares - são alternativas buscadas contemporaneamente na perspectiva de criação de um projeto que faça frente ao modelo privatista e empresarial de cidade imposto pelos grupos econômicos, políticos e sociais hegemônicos (VAINER, 2014). Neste sentido, o direito de resistência supõe que seu exercício seja favorável ao gozo de direitos primários, como é o caso do direito à vida, do direito à dignidade humana e do direito à propriedade. Sua justificativa reside na violação de algum direito primário.

As transformações no espaço urbano da cidade do Rio de Janeiro vêm causando uma série de impactos em diferentes dimensões do habitar na cidade; impactos esses que reduzem ou ressignificam direitos humanos. Dentre esses direitos, destaca-se o direito à cidade. Ao ganhar nova roupagem nos dias atuais, o direito à cidade mascara-se, limitando-se, na ótica governamental e empresarial, ao direito de acesso aos serviços, equipamentos e mercadorias proporcionados pela cidade capitalista. Maiores protagonistas deste ressignificado direito à cidade, reduzido apenas ao acesso individual ou de fragmentos de camadas sociais, os empreendedores urbanos seduzem facilmente seus eleitores-clientes a aceitarem que vale tudo para a prática de um direito à cidade nestes moldes, inclusive priorizar os interesses das empreiteiras e fazer da cidade um constante canteiro de obras.

A apropriação privada da cidade do Rio de Janeiro, ao adotar o empreendedorismo urbano, caracterizou-se pela articulação dos interesses do Estado, do capital imobiliário, do capital fundiário e do capital comercial (ROLNIK, 2004; HARVEY, 2012), e peca em deixar de fora desse processo os principais interessados na cidade: seus habitantes.

O que se questiona aqui é justamente o fato de essas intervenções contradizerem, no plano da realidade, o processo democrático de planejamento urbano, conforme proposto pelo Estatuto da Cidade, lei federal que norteia o desenvolvimento das cidades brasileiras (BRASIL, 
2001). Os cidadãos cariocas vivem em situação de nítida violação aos direitos humanos e ao direito à moradia digna, materializada na falta de ampla divulgação das ações públicas e de possibilidades de envolvimento dos atores locais no debate sobre os projetos de urbanização desenvolvidos pela Administração Pública Municipal do Rio de Janeiro.

A remoção dos moradores pela Prefeitura para bairros distantes da cidade vem quebrando gradualmente redes de sociabilidade que muito dificilmente serão substituídas ou restabelecidas. Pior, a remoção de moradores, não só da Comunidade Metrô-Mangueira, mas de qualquer outra área da cidade, vai contra os princípios da Lei Orgânica Municipal, ao prever, em casos de remoção, a responsabilidade da Prefeitura em buscar, previamente, uma área próxima da atual residência das famílias ${ }^{5}$.

No que tange à resistência da população carioca, o ano de 2013 certamente será lembrado na história do país pelo ciclo de mobilizações populares que tomaram conta das ruas, e cujas bandeiras estão relacionadas à reivindicação de direitos correlatos ao direito à cidade, como: mobilidade urbana (as primeiras manifestações pleiteavam a diminuição do preço da tarifa de ônibus); educação de qualidade (a greve dos professores municipais e estaduais durante o mês de outubro levou multidões às ruas); moradia digna (não às remoções forçadas); mais investimentos na saúde pública etc..

Os protestos que levaram milhares de brasileiros às ruas contra o aumento de vinte centavos na tarifa de transporte público expuseram inúmeras insatisfações, resumidas na frase "muito mais que vinte centavos", intensificadas no grito "queremos escolas e hospitais padrão FIFA" e, posteriormente, ressignificada pela grande mídia numa cruzada contra a "corrupção". A decisão do então prefeito do Rio de Janeiro, Eduardo Paes, no dia 19 de junho de 2013, de reduzir as tarifas de transporte público ${ }^{6}$ (de 2,95 voltou a custar 2,75), que resultou numa vitória objetiva, tanto para os manifestantes quanto para o restante da sociedade, sem se esquecer que o transporte público é um dever do Estado (art. 30, inc. V), como preceitua a

\footnotetext{
${ }^{5}$ Art. 429 - A política de desenvolvimento urbano respeitará os seguintes preceitos: $[\ldots]$ VI - urbanização, regularização fundiária e titulação das áreas faveladas e de baixa renda, sem remoção dos moradores, salvo quando as condições físicas da área ocupada imponham risco de vida aos seus habitantes, hipótese em que serão seguidas as seguintes regras: a) laudo técnico do órgão responsável; b) participação da comunidade interessada e das entidades representativas na análise e definição das soluções; c) assentamento em localidades próximas dos locais da moradia ou do trabalho, se necessário o remanejamento;

6 Posteriormente houve novo aumento. A nova tarifa passou a custar R\$3,00 em 08/02/2014. Informação disponível em: <http://ultimosegundo.ig.com.br/brasil/2014-06-04/de-14-capitais-quereduziram-tarifa-do-transporte-publico-5-ja-tiveram-aumento.html>. Acesso em: 3 abr. 2018.
} 
Constituição brasileira; ainda assim, o resultado concreto alcançado pelos manifestantes não foi suficiente para arrefecer a insatisfação que continuava incendiando as ruas cariocas, reforçando a hipótese de a motivação ser por muito mais que os vinte centavos.

Acreditando no esvaziamento natural dos movimentos de protesto, os governos do Município e do Estado Rio de Janeiro foram surpreendidos com a crescente mobilização, preferindo apostar na truculência da Guarda Municipal e da Polícia Militar para calarem as inúmeras vozes que gritavam pelas ruas. O efeito foi completamente inverso ao pretendido: as ruas refletiram solidariedade e identificação com os feridos e oprimidos, elevando exponencialmente o número de insatisfeitos e de insatisfações, o que contribuiu para emergir uma complexa multiplicidade de pautas. As imagens divulgadas pelas redes sociais detonaram a indignação popular e confrontaram o discurso de "vandalismo" propalado pela mídia tradicional, que insistentemente recorreu aos termos "invasão", "saque" e "vandalismo" para noticiar os protestos. Ainda que a empatia tenha sido responsável por arregimentar milhares de pessoas, o caráter difuso das manifestações acabou levando muitas autoridades, perplexas diante do volume de insatisfações, a transferirem para os manifestantes a responsabilidade pela inviabilidade na construção de acordos e consenso, atribuída à ausência de diálogo provocada pela liderança horizontal, adotada pela maioria dos movimentos de protestos (ROLNIK, 2015).

A insatisfação restou evidente durante a abertura da Copa das Confederações ${ }^{7}$, quando cerca de 300 manifestantes ocuparam os arredores do Estádio do Maracanã para protestarem contra a opção do governo, preferindo concentrar os gastos públicos com a construção dos estádios, em detrimento de setores prioritários, como educação e saúde. A exposição do dissenso popular contrastou com a crença nas decisões acertadas e a importância creditada ao país, ratificada perante a escolha da capital fluminense como sede da Jornada Mundial da Juventude pela cúpula da Igreja Católica, além da eleição do Rio de Janeiro para recepcionar os Jogos Olímpicos de 2016. Ao contrário do pretendido, a visibilidade do país acabou contribuindo para expor as mazelas do Estado.

Se no ano de 2013 a Cidade Maravilhosa foi palco de grandes eventos, como a Copa das Confederações e a Jornada Mundial da Juventude, igualmente se tornou cenário para manifestações que, quase diariamente, ocuparam o espaço urbano com múltiplas e divergentes demandas e formas de protestar. A insatisfação evidenciada nas ruas deixa claro que a

\footnotetext{
${ }^{7}$ A Copa das Confederações, inaugurada no dia 16 de junho de 2013, foi uma estratégia previsível e globalmente utilizada por movimentos que aproveitam a visibilidade dos eventos para potencializar o protesto.
} 
população não aprovou os altos investimentos na adaptação da cidade para receber os megaeventos esportivos, deixando de serem investidos recursos em demandas sociais como moradia, saúde e educação. Tamanha mobilização social, denominada de "jornadas de junho", teve início nas véspera da Copa das Confederações, no mês de junho de 2013, e representou uma ameaça ao modelo empreendedorista de gestão. Isso pode ser percebido pela grande repressão policial às manifestações e pela movimentação dos patrocinadores da Copa do Mundo FIFA, que passaram a exigir garantias do governo brasileiro de que as mobilizações não afetassem a realização dos jogos (MARICATO, 2014).

Recepcionar megaeventos traz para os parceiros privados, através das Parcerias Público-Privadas (PPP), a garantia legal (Lei n. 11.079/2004) de que os contratos assinados sejam cumpridos dentro dos prazos acordados. No entanto, o que é bom para o parceiro privado pode não ser bom para a sociedade, pois não apenas os benefícios coletivos são mais restritos, mas também, e principalmente, alguns direitos sociais podem ser - e estão efetivamente sendo - atacados, como é o caso do direito à moradia dos residentes em áreas no caminho das obras ou até mesmo apenas próximas desses territórios. A radical inflexão na política urbana municipal influencia intensamente o cotidiano das comunidades pobres estabelecidas nos traçados das obras de renovação urbana desenvolvidas em decorrência dos megaeventos.

Ao analisar o caso da Comunidade Metrô-Mangueira, Meireles (2018) observa que a atuação coletiva do NUTH, mesmo que não tenha adentrado a esfera judicial em um primeiro momento, tornou possível a abertura de um canal de diálogo da comunidade com a Prefeitura e surtiu efeitos positivos na garantia do direito à moradia, conquistando para a maioria dos moradores um reassentamento mais próximo. Com a segunda intervenção na Comunidade Metrô-Mangueira em 2015, a judicialização por meio de uma ação coletiva ${ }^{8}$ assegurou a permanência da comunidade no local e, posteriormente, abriu um canal extrajudicial de negociações.

A organização comunitária atualmente começa a discutir a proposição de um projeto alternativo para as obras de adaptação da cidade para os grandes empreendimentos e os megaeventos, que dê voz aos moradores e concilie o desenvolvimento à sua permanência e da cultura local.

\footnotetext{
8 Processo n 0 0353755-33.2015.8.19.001
} 


\section{A DINÂMICA DA RESISTÊNCIA DA COMUNIDADE METRÔ-MANGUEIRA}

Em conjunto com o discurso da ordem urbana e do progresso da cidade, e na proximidade da realização dos megaeventos, diversas comunidades foram removidas ${ }^{9} \mathrm{em}$ desrespeito aos direitos humanos dos moradores. São exemplos emblemáticos as comunidades como a da Vila Autódromo, situada ao lado do extinto Autódromo Internacional Nelson Piquet e atual Parque Olímpico; as da Restinga, da Vila Harmonia e da Vila Recreio, todas localizadas na Avenida das Américas, onde foram realizadas as obras da Via Transoeste; os casarões no Largo do Campinho, por onde passou a via chamada de Transolímpica; ou a Comunidade MetrôMangueira, próxima ao Estádio do Maracanã, na qual o município distribuiu laudos de interdição genéricos, sem realizar vistorias técnicas nas casas, e sequer apresentou um projeto de urbanização para a área, havendo, em princípio, somente as suspeitas dos moradores de que ali seria construído um estacionamento para o "novo Maracanã".

Nas práticas de remoções forçadas é clara a violação aos direitos humanos por várias razões: ausência de informação à população aliada à coação dos moradores a fim de que aceitem as propostas feitas pela Prefeitura; realização de demolições antes de ser definido o reassentamento; ausência da participação da comunidade na discussão sobre os projetos de reurbanização; indenizações insuficientes, não sendo possível que as famílias adquiram outro imóvel com os valores recebidos; e uso do Judiciário contra o cidadão, havendo despejos sem aviso prévio, agressões e ameaças no momento da remoção e demolição de parte da comunidade para coagir aqueles que ainda ofereciam resistência (GUARIENTO, 2015).

As violações aos direitos humanos após as remoções são igualmente cruéis, podendo-se citar: dificuldades de acesso à cidade, hospitais, serviços de saúde e perda da fonte de renda familiar em razão da distância dos conjuntos habitacionais do local onde as famílias exerciam suas atividades laborais anteriormente; crianças sem escola devido à falta de vagas nos locais para os quais as famílias foram levadas; e quebra de vínculos com amigos e familiares.

A Comunidade Metrô-Mangueira, objeto deste estudo, tem aproximadamente 40 anos de existência. Na sua área foi construído um polo automotivo, com 96 pontos comerciais e um parque arborizado com academia para idosos, parque infantil, ciclovia e pista de skate, obra cujo custo foi estimado em $\mathrm{R} \$ 30,5$ milhões.

\footnotetext{
${ }^{9}$ O Observatório das Metrópoles afirma que, em todo o país, cerca de 200 mil pessoas foram removidas em razão das obras para receber os megaeventos. No caso do Rio de Janeiro, 10 mil famílias foram removidas.
} 
Antes das remoções, a comunidade acolhia aproximadamente 700 famílias. Muitas delas (aproximadamente 108 famílias) foram levadas em 2012 para um conjunto habitacional em Cosmos (Zona Oeste); 246 famílias para o conjunto habitacional Mangueira I, que foi construído no entorno da comunidade; 216 famílias para um segundo conjunto habitacional, Mangueira II, também localizado no entorno comunidade; e 92 famílias em Triagem.

Cerca de 40 famílias permaneceram no local, convivendo com escombros e completa falta de estrutura e abandono pelo poder público até que questões burocráticas junto à Caixa Econômica Federal fossem solucionadas. A construção dos conjuntos habitacionais Mangueira I e II pode ser entendida como conquista decorrente da resistência oferecida pelos moradores da comunidade, pois inicialmente não existia essa previsão. Em princípio, 108 famílias foram levadas para a Zona Oeste (distante $50 \mathrm{~km}$ da comunidade) e somente após muita pressão dos moradores foram construídos os dois conjuntos habitacionais (MANTELLI et al., 2015).

Em 2014, as famílias que ainda não tinham sido reassentadas permaneciam no local, entre escombros, e nenhuma obra tinha sido iniciada. Nesse mesmo ano, sem nenhum aviso prévio, doze casas ainda habitadas foram demolidas, sem apresentação de qualquer solução para o reassentamento destas pessoas, o que gerou protestos, indignação e repressão violenta por parte da Polícia Militar (MANTELLI et al., 2015).

É difícil fazer frente ao poderio bélico do Estado, mas sem resistência certamente os resultados das remoções dos moradores da Comunidade Metrô-Mangueira teriam causado maiores danos à população. As assembleias organizadas por moradores da comunidade, as audiências públicas e a articulação com distintos atores que aderiram à causa foram importantes estratégias para assegurar a parte dos moradores da Comunidade MetrôMangueira o reassentamento nos conjuntos habitacionais Mangueira I e II, o que, apesar de não ser o desejado pela comunidade, era o que traria menor impacto. Assim, é importante avançar em políticas públicas que assegurem os direitos humanos dos cidadãos que vivem em comunidades ameaçadas e sofrem com as intervenções e violações promovidas pelo poder público.

\section{O PERFIL DOS SUJEITOS DA RESISTÊNCIA NA COMUNIDADE METRÔ-MANGUEIRA}

A maioria dos comerciantes entrevistados (sete pessoas) vive há mais de 16 anos na comunidade, apresentando como justificativa maior para esta fixação a existência de sua atividade profissional. Da mesma forma, apresentam como razão predominante para esta 
permanência o fato de terem implantado e desenvolvido as atividades comerciais atualmente existentes, cujo funcionamento também já vigora há mais de 16 anos. Cinco pessoas são proprietárias dos respectivos negócios e quatro entrevistados revelam serem trabalhadores autônomos, com a predominância de oficinas mecânicas (cinco estabelecimentos), vendas de autopeças (quatro lojas) e borracharia (uma loja). Os serviços voltados para veículos automotores se justificam pela proximidade com as importantes artérias de tráfego intenso naquela região.

As questões pertinentes a essa área de interesse podem ter gerado dúvida a pelo menos um entrevistado, pois um vendedor ambulante mencionou desempenhar diversas atividades no local, quando a Prefeitura decidiu que deveria sair do local, tais como: padaria, mercado de alimentos, de roupas, de material de construção, oficina e venda de autopeças. Talvez ele tenha desejado expressar que havia um comércio diversificado na comunidade que foi banido com a ação da Prefeitura.

O movimento existente no comércio parece oferecer rentabilidade suficiente para, pelo menos, assegurar a subsistência das famílias dos comerciantes e trabalhadores, formadas por seis ou mais pessoas (seis casos) ou de três a cinco pessoas (três casos). Pela amostragem foi possível constatar que a suspensão das atividades profissionais destes participantes iria causar um sério problema social para as famílias dos moradores, pois impedidos de acesso a seus meios preferenciais de subsistência.

Outro aspecto relevante também detectado na pesquisa foi a maneira pela qual os comerciantes e trabalhadores receberam a comunicação do processo de remoção a ser empreendido pela Prefeitura. Apenas um dos entrevistados menciona ter sido notificado pessoalmente por funcionários da Prefeitura, enquanto quatro ficaram sabendo da notícia em conversas com os vizinhos, dois foram avisados pela Associação dos Moradores e outros dois alegam não terem recebido comunicação alguma. Levando em conta estes depoimentos, caracteriza-se o descaso com que o processo de remoção foi proposto, pois a comunicação formal e antecipada da Prefeitura, nos moldes previstos em lei, seria condição sine qua non para os moradores se prepararem para a mudança ou para pleitearem seus direitos.

Esta comunicação precária também é responsável pela falta de uma percepção comum dos comerciantes e trabalhadores sobre qual seria a proposta da Prefeitura para a desocupação da área e sobre seu destino após o processo. Quatro entrevistados entenderam que iriam se instalar em outro local da comunidade, enquanto um compreendeu que teria de sair de lá sumariamente. Também se diversificam as opiniões sobre o que iria ocorrer após a 
desocupação, surgindo as seguintes hipóteses: demolição, construção de novas lojas e residências ou indenização dos moradores. Porém, houve quase unanimidade na percepção de que em nenhum momento a Prefeitura considerou os interesses dos entrevistados, pois seis já eram moradores do local e quatro desempenhavam apenas atividades profissionais naquela área, mas não tinham sido ouvidos sobre suas necessidades e perspectivas.

A partir desta condução coercitiva do processo por parte da Prefeitura, os comerciantes e trabalhadores tiveram de se reinventar para a continuidade de seu sustento e das suas famílias. Apenas três conseguiram manter-se na mesma atividade; dois mudaram de atividade, entre os quais um tornou-se motorista do Uber; outro teve de se instalar fora da comunidade. Os sete que eram moradores conseguiram permanecer no local, porque houve decisão favorável do Judiciário, porém três tiveram de sair, pois o prédio foi imediatamente demolido, retirando-Ihes a fonte de sustento.

Vale destacar o papel da Associação dos Moradores na resistência esboçada por estes cidadãos "rebeldes com causa" na luta por seus direitos de trabalho e moradia. A maioria (oito entrevistados) reconhece que a Associação exerce uma condição de liderança ativa e todos os dez responderam que admitem procurar as lideranças para lutar pela defesa de seus interesses. As formas com que se organizam em torno dos interesses comuns são variadas: acompanhamento das lideranças nas reuniões com as autoridades da Prefeitura - sete indicações; comparecimento às manifestações de protesto contras medidas que thes desagradam - seis indicações; frequência às reuniões na Associação dos Moradores - cinco indicações; mobilização da Associação dos Moradores para resolução de problemas afetos à comunidade - quatro indicações; e apresentação de propostas para a resolução de problemas que incomodam os moradores - três indicações.

Com tal repertório de manifestações em prol de seus interesses, os sujeitos da Comunidade Metrô-Mangueira demonstram um alto nível de mobilização que contribui significativamente para exigir o direito de continuarem ocupando a região, apesar das ações em contrário da Prefeitura. É a constatação de nove entrevistados sobre o movimento conjunto de comerciantes, trabalhadores e moradores no desejo de continuarem na comunidade. Neste sentido, os cidadãos "rebeldes com causa" objetivaram demonstrar cabalmente à Prefeitura e à sociedade seu desejo de permanecerem no local, mediante as seguintes formas de protesto: manifestações em locais públicos - oito indicações; recurso interposto no Judiciário - sete indicações; reuniões na Associação dos Moradores - sete indicações; apresentação de 
propostas alternativas para a resolução do problema da remoção - seis indicações; e acompanhamento da liderança nas reuniões com autoridades da Prefeitura - cinco indicações.

Para ilustrar a gravidade da situação, vale transcrever o segmento de uma reportagem feita à época pelo jornal O Globo (2014), quando as manifestações mais se radicalizaram:

\section{Moradores fizeram protestos}

Na noite desta quinta-feira, pelo terceiro dia consecutivo, moradores da Favela Metrô-Mangueira voltaram a fechar a Avenida Radial Oeste. Policiais do Batalhão de Choque (BPChq) e do 4ํㅡ BPM (São Cristóvão) ocuparam a comunidade para garantir as demolições. Parte dos moradores ameaçou fazer uma barreira humana no acesso à área, onde um grupo montou barricada. Mais cedo, por volta de 8h, a circulação da Linha 2 do metrô foi paralisada durante cerca de 10 minutos, no trecho entre as estações de Triagem e São Cristóvão. Segundo informações da concessionária Metrô Rio, a energia teve de ser cortada depois que manifestantes começaram a jogar entulho e tijolos na linha férrea.

Merece registro a atuação veemente dos comerciantes, trabalhadores e moradores na preservação de seus direitos, ao demonstrarem plena consciência de que a fixação de suas atividades e moradias há mais de dez anos na comunidade significa uma parcela valiosa de sua vida aplicada em esforço e dedicação, credenciando-os para manterem seu status de legítimos proprietários dos imóveis ou usuários preferenciais do local. Em sua defesa manifestam-se com as seguintes justificativas de permanência: a necessidade de permanecer próximo ao local de trabalho e tomar conta do patrimônio destinado ao comércio; a conquista e o exercício dos direitos ao trabalho e à moradia; o benefício de estar perto do trabalho e o fato de já ter vida estabelecida no local; a necessidade premente de trabalhar; o fato de considerar justa sua pretensão de permanência no local; a frase "somos queridos na região", manifestando o teor da inclusão da comunidade nos bairros adjacentes; e a frase "o sol nasce para todos", repudiando qualquer tentativa de exclusão por parte da Prefeitura.

A iminência dos Jogos Olímpicos foi o grande marco alegado para justificar as mais recentes e reiteradas tentativas da Prefeitura em levar adiante o processo de remoções, eis que, após o evento, sete entrevistados não notaram nenhuma participação neste sentido, enquanto apenas três manifestaram que houve uma tentativa já em 2017. Ainda assim, esta única tentativa os mobilizou novamente para o protesto nas ruas, as reuniões na Associação dos Moradores, na indicação de propostas para a resolução do problema e a subsequente recorrência ao Judiciário. É interessante registrar que uma entrevistada mencionou que não houve tentativa da Prefeitura em tirar os moradores da comunidade em função das Olimpíadas, mas logo em seguida afirmou que ocorreram os protestos em questão. 
Apesar de a situação ter sido pacificada com a intervenção do Judiciário que concedeu liminar para conter as remoções, paira ainda na comunidade um clima de revolta pela atuação da Prefeitura, quando os comerciantes, trabalhadores e moradores demonstram continuarem mobilizados para confrontarem os órgãos governamentais na tentativa de tomarem medidas contra seus interesses. Com esta afirmativa concordam nove entrevistados da pesquisa, fundamentando-se nos seguintes argumentos: tais medidas são ilegais e injustas, pois não contam com o consentimento das pessoas; são medidas ilegais e representam abuso de poder por parte da Prefeitura; sempre é necessário defender os próprios direitos; trata-se de um caso para exigir respeito à justiça e à democracia; e na experiência vivenciada, a Prefeitura demonstra que age de forma arbitrária e agressiva, visando apenas a atender interesses alheios aos da comunidade.

Em função do desgaste sofrido com o governo anterior, os entrevistados manifestaram sua expectativa com relação à gestão da Prefeitura empossada em 2017, no sentido de pavimentar um novo relacionamento que assegure os direitos e os destinos da Comunidade Metrô-Mangueira: a organização e construção de um polo automotivo e a realização de outras melhorias desejadas no local; evitar a remoção de quem está no local e providenciar a construção de novas lojas; urbanização do espaço público, conservando as lojas remanescentes; e que as lojas já construídas sejam doadas a quem teve as suas demolidas.

\section{O DESCASO POLÍTICO: O PROCESSO DA DESIMPORTÂNCIA DA COMUNIDADE METRÔ- MANGUEIRA}

Segundo dados do Banco Mundial publicados em fevereiro de 2017, o número de pobres no Brasil atingiria, numa previsão mais "otimista", o quantitativo preocupante de 19,8 milhões de pessoas neste mesmo ano, sendo que 8,5 milhões seriam classificados como estando na linha de extrema pobreza. Caso fundada numa previsão pessimista, a instituição acredita que chegaria a 20,9 milhões a quantidade de pobres, sendo 9,4 milhões em estado de miséria (MARIZ, 2017). Esta situação deriva da recessão econômica sofrida pelo país nos últimos anos, mas também pela incúria dos governantes brasileiros que, historicamente, têm olhado com indisfarçado descaso para esta camada da população.

O geógrafo Milton Santos (2001), em seus estudos sobre a globalização, designa que existem três formas de pobreza que implicam o surgimento de três formas de dívida social: 
a) pobreza incluída - pode ser acidental, residual ou sazonal e ocorre em função de algum acontecimento periódico, tornando-se mais fácil de ser gerida a partir do momento em que puderem ser dissipadas suas causas;

b) marginalidade - produzida principalmente por questões econômicas, como as relacionadas à divisão do trabalho. Também podem ser resolvida, desde que os governos se mobilizem para estimular iniciativas para a redução do desemprego, por exemplo;

c) pobreza estrutural - não é local, nem nacional, mas é globalizada, pois é provocada por aspectos econômicos, cujo corolário é a lógica neoliberal de acumulação de capital, em lugar de sua redistribuição pelos estratos mais necessitados. "Nessa última fase, os pobres não são incluídos nem marginalizados, eles são excluídos" (SANTOS, 2001, p. 69; 72).

O artigo de O Globo mencionado anteriormente informa que, desde 2015, vem crescendo no Brasil a legião dos "estruturalmente pobres", segundo o conceito formulado pelo Banco Mundial e estipulado por Milton Santos. Essa parcela expressiva da população apresenta maior dificuldade em melhorar sua qualidade de vida diante da alta competitividade do mercado de trabalho, pois é menos escolarizada (apenas 17,5\% com ensino médio), possui mais idade (média de 41 anos do chefe de família) e tem presença importante na área rural (36\%). Trata-se de uma população candidata a se tornar clientela preferencial para os programas sociais (MARIZ, 2017).

Apesar desse quadro pintado com cores soturnas, os sucessivos governos adotam uma matriz ideológica fundada nos princípios do neoliberalismo (MULATINHO, 2016) - nas esferas federal, estadual e municipal -, que os levam a tratar a situação econômica brasileira sem levar em conta as questões sociais como uma de suas prioridades. Em vez disso, a gestão pública age como se a população pobre fosse invisível, como lembra o psicólogo Fernando Braga da Costa autor do livro Homens invisíveis: relatos de uma humilhação social, no qual trata do tema com singular propriedade - em entrevista concedida à Agência Brasil:

"A invisibilidade está presente de tal forma que se tornou algo normal. O fato de ser normal não quer dizer mais nada além do fato de que estamos habituados", acrescenta. Para Costa, o Estado no Brasil está localizado de forma tão longínqua dos cidadãos que parece muito mais um jogo de esconde-esconde. "O Estado não cuida dessas pessoas [pobres] porque não há interesse humano nisso" e "acaba prevalecendo o interesse de uma classe hegemônica dominante" (COSTA, 2012).

Na contrapartida da mencionada invisibilidade com relação à população mais pobre, há uma preocupação clara e definitiva em dar respostas ao mercado, mediante decisões que possam atender às demandas das empresas e à atração de investidores interessados em 
resultados a serem auferidos pela inversão do capital especulativo no potencial de negócios oferecidos nas diversas regiões do país. Daí o pessimismo quanto à reversão do quadro de pobreza que assola o país, apesar das medidas anunciadas pelo Poder Executivo como as mais eficazes no sentido de melhorar a situação socioeconômica brasileira (COSTA, 2012).

Quando enfocada a situação da Comunidade Metrô-Mangueira, constata-se que ocorreu descaso político semelhante ao panorama descortinado em nível macroeconômico, mormente na interface dos interesses dos seus moradores com as intenções da Prefeitura e dos promotores imobiliários, no encaminhamento do processo de gentrificação, durante a preparação e a implementação das etapas para realizar os megaeventos Copa do Mundo de 2014 e Jogos Olímpicos de 2016.

No que tange aos processos de gentrificação, tal como observados por Neil Smith (2006), constata-se a intenção comum do poder público em deslocar para a periferia os moradores populares dos centros urbanos, a fim de facilitar sua maior valorização. O autor assim comenta a respeito dessa evacuação compulsória e generalizada:

A gentrificação produz agora paisagens urbanas que as classes médias e médias altas podem "consumir" - uma vez que os sem-teto foram rapidamente evacuados e que contribuem para a formação de identidades de classe através de um espectro de classes significativo, ainda que de maneiras muito diferenciadas.

Do mesmo modo que a televisão popular faz as massas acreditarem que as vidas das pessoas ricas e célebres representam a norma social à qual todo mundo pode aspirar, a gentrificação produz agora uma paisagem urbana que veicula as mesmas aspirações (SMITH, 2006, p. 73).

Por outro lado, a escalada para desfrutar essa paisagem se torna cada vez mais íngreme, à medida que os cidadãos pobres são despojados dos meios preferenciais para o acesso à utopia do desenvolvimento social disseminada pela própria ideologia capitalista: moradia, alimentação, estudo, trabalho e renda.

A observação de Neil Smith (2006) é corroborada pela situação dos moradores da Comunidade Metrô-Mangueira, diante da realização dos megaeventos. Removidos de suas moradias, o que restou a eles foram a festa, o glamour dos atletas e celebridades que desfrutaram das competições, a beleza e suntuosidade das edificações construídas para encantar o mundo com a pujança carioca e brasileira. Todas essas performances ficaram ainda mais sedutoras quando narradas mediante os recursos tecnológicos da grande mídia empresarial. Embora existissem, em paralelo, manifestações de desagrado com toda essa exuberância, não mereceram o mesmo apreço da mídia que o dedicado às celebrações. Muito pelo contrário, as manifestações foram estereotipadas como "anarquia", além de geradoras de 
"violência" entre os participantes e a polícia, aparecendo nos jornais e nas emissoras de televisão em momentos aleatórios e sempre asfixiadas pela massiva propaganda da realização dos megaeventos e dos seus patrocinadores (SMITH, 2006).

Já Raquel Rolnik (2004) percebe nessa ação que o poder público exerce um insofismável movimento de segregação, quando impõe a remoção de moradores como solução para os preparativos dos megaeventos. Iniciativas deste tipo cavam um fosso ainda mais profundo para agravar a desigualdade social. No caso da citada comunidade, identifica-se a intenção da Prefeitura em segregar a pobreza em locais que considerasse mais propícios, ou seja, onde pudesse estender um longo véu que a ocultasse das lentes das câmeras de televisão e de fotografia, especialmente da imprensa estrangeira, tão frequentes nas cercanias do Estádio do Maracanã. Assim, estaria consolidada a imagem do Brasil como mercadoria vendável na comunidade internacional, enquanto país emergente de onde a pobreza estivesse definitivamente erradicada.

Outro aspecto que vem confirmar o descaso político é o fato de a comunidade já contar 35 anos naquele espaço e, ao longo de todo esse tempo, o poder público pouco ou nada fez para melhorar as condições de vida da população. Porém, o advento dos megaeventos teve a virtualidade de fazer a Prefeitura despertar da sua inércia, não para melhorar o espaço, mas visualizá-lo na perspectiva de seu alto potencial de valorização. Como lembra Raquel Rolnik:

Como a valorização ou a desvalorização de uma região depende dos investimentos públicos e privados naquele espaço, o investimento maciço, representado por grandes trabalhos de remodelação, altera substancialmente o mercado imobiliário. Assim, as grandes obras públicas de redesenho da cidade funcionam como territórios reconquistados ou frentes pioneiras para o capital imobiliário. [...]. Trata-se, portanto, de uma atualização da renda fundiária (ROLNIK, 2004, p. 63).

A ação subsequente à do "território reconquistado" pela Prefeitura seria sua pronta entrega para as empresas de obras públicas, a fim de lhe acrescentar os equipamentos urbanos que produzissem a merecida "atualização da renda fundiária", bem ao gosto dos princípios do mercado imobiliário.

Diante dessa "prioridade governamental", existem outras táticas de convencimento para remover os moradores. Além das ações traumáticas registradas amplamente na imprensa, percebe-se o descaso da municipalidade também na maneira subliminar na tática para provocar a saída dos moradores, ao juntar à desapropriação da moradia, que está em nível da perda material, o desgaste psicológico com a diminuição da autoestima, pela perda de identidade com lugar onde viveram durante muitos anos. Os moradores se sentem desamparados até mesmo 
pelas instituições que, a priori, teriam como missão cuidar dos seus interesses e necessidades enquanto cidadãos. Órfãos do Estado tornam-se presa fácil para se submeterem às intenções da especulação imobiliária que, por sua vez, conta com todas as benesses da Prefeitura, sua fiel parceira.

Como um grand finale para todo esse processo de descaso do governo do ex-prefeito Eduardo Paes, surge o relato sobre os procedimentos das remoções e do reassentamento, reunidos por Daniela Ferreira Oliveira em sua pesquisa acadêmica com o título de Qualidade de vida em habitação de interesse social: caso Metrô-Mangueira. A autora registra as condições das novas residências oferecidas aos ex-moradores de comunidades:

Historicamente, os reassentamentos são implantados nas periferias das cidades, em locais de difícil acesso, com baixa oferta de equipamentos e serviços urbanos. Nessas áreas o preço da terra é mais baixo por estar situado, quase sempre, distante da malha urbana central e também pela região não apresentar infraestrutura urbana consolidada. [...].

Observa-se que esse tipo de problema é histórico e ocorre com frequência no Brasil inteiro. A periferização está relacionada a diversos e complexos fatores, dentre eles, a grande distância das áreas aspiradas pelas construtoras, a ausência de infraestrutura, a distância da região metropolitana são os mais destacados. As terras urbanizadas nas grandes cidades são escassas e caras por terem maior centralidade (OLIVEIRA, 2015, p. 43).

Com os ex-moradores da Comunidade Metrô-Mangueira não foi diferente. Conforme explica a mesma autora, os moradores foram desrespeitados em seus direitos, pois as remoções foram realizadas de forma irregular e arbitrária. A decisão foi tomada sem a mínima participação aos moradores, sem ocorrerem reuniões prévias ou negociação sobre o que seria oferecido pelo reassentamento. Não houve procedimento jurídico adequado, pois não se reconheceu o direito de usucapião dos ocupantes dos terrenos, que residiam lá há mais de cinco anos, sem que houvesse contestação da posse. Com isso, foram oferecidos apenas $80 \%$ do valor do imóvel em juízo (OLIVEIRA, 2015).

A justificativa criada pela Prefeitura para as remoções foi a de que a comunidade estava em área de risco, por ficar junto à linha de trem, fato que, por si só, há tempos já impunha a necessidade de reassentamento das pessoas que lá moravam. Porém, é de se notar que o perigo só ficou maior quando a Prefeitura demoliu parte das casas e, de propósito, deixando o local em ruínas e as moradias remanescentes com a estrutura abalada, em risco de se desmoronar a qualquer momento (OLIVEIRA, 2015).

O plano inicial era encaminhar os moradores sumariamente para conjuntos habitacionais na Zona Oeste da cidade. Diante da insatisfação generalizada, a possibilidade de 
interferir no processo só foi obtida após uma série de manifestações que pavimentaram a resistência das famílias em saírem do local, ganhando maior visibilidade por parte da sociedade para o problema criado pela Prefeitura (OLIVEIRA, 2015).

Ainda segundo Daniela Ferreira Oliveira, as 106 famílias iniciais foram removidas, em 2011, para um conjunto habitacional do Programa Minha Casa Minha Vida, situado em Cosmos, a $60 \mathrm{~km}$ da comunidade, o que significou um afastamento compulsório do local de trabalho de diversos moradores que ainda dependiam dos antigos empregos para a sobrevivência. Após uma série de protestos e reivindicações, 248 famílias conseguiram, em 2012, serem reassentadas no Conjunto Habitacional da Mangueira, este sim mais próximo do antigo endereço, pois está situado em frente à Comunidade da Mangueira. Outras 65 famílias foram para Triagem, distante $3 \mathrm{~km}$ da antiga comunidade (OLIVEIRA, 2015).

Os moradores que optaram por continuar na comunidade passaram a conviver com o aumento dos casos de violência no local. Com a demolição das casas desabitadas, a comunidade se transformou num grande monturo de escombros e entulhos, à semelhança de uma cidade arrasada pela guerra, fazendo com que traficantes e usuários se reunissem no lugar para vender ou consumir entorpecentes (OLIVEIRA, 2015, p. 55). Estas condições insalubres ainda se tornaram piores, com a proliferação de insetos, poças de água, muita poluição e um cheiro insuportável, deixando o local irrespirável.

Quanto ao sentimento despertado pelas novas residências junto aos moradores reassentados, os relatos são diversos. No que se refere à qualidade das moradias, houve algumas queixas nos Condomínios da Mangueira sobre rachaduras e vazamentos nos apartamentos, enquanto no Bairro Carioca, situado em Triagem, não foi registrado nenhum problema nesse sentido. Porém uma questão extremamente preocupante foi a segurança pública, conforme a autora discorre adiante:

Embora a porcentagem em relação à insegurança e violência tenha sido baixa, muitas famílias relataram a presença de tráfico de drogas nos empreendimentos. Nos condomínios da Mangueira, de acordo com os síndicos, a presença da polícia é quase que diária, pois a mesma leciona aulas de reforço escolar para os moradores dos condomínios. Já no Bairro Carioca, a situação é pior. O medo das famílias é maior, pois há grupos de diferentes facções que disputam o poder dentro do empreendimento. Além disso, durante a noite as pessoas evitam sair de casa devido à presença de viciados em crack. Para se ter uma ideia, a cabine da guarda municipal que ficava dentro do empreendimento foi depredada pelos traficantes e após esse incidente não houve mais guarda municipal no local. De acordo com relatos, as famílias se sentem abandonadas pelo 
Poder Público no quesito segurança no Bairro Carioca (OLIVEIRA, 2015, p. 80).

Este processo de desapropriação, remoção e assentamento promovido pela Prefeitura, além de ser realizado de maneira intempestiva, despertou nas pessoas uma forte insatisfação que veio se agravar em revolta, conforme eclodida nas manifestações de rua.

A posição da atual gestão da Prefeitura não é manifestada na mídia. Portanto, buscouse identificá-la a partir de entrevista realizada, no âmbito desta pesquisa, em julho de 2017, com o subsecretário de Infraestrutura, Sebastião Bruno, integrante da equipe do prefeito Marcelo Crivella. Procurou-se saber sobre as perspectivas do que viria a ocorrer com o espaço do qual os moradores da Comunidade Metrô-Mangueira foram sumariamente removidos. Interessava conhecer o destino a ser dado àquele território, depois da encarniçada batalha para conquistá-lo e mantê-lo, com ingente sofrimento das famílias que lá estavam. Adiante são relacionadas as questões formuladas durante a entrevista e a imediata resposta do subsecretário:

sobre os planos da atual gestão da Prefeitura para a construção do Polo Automotivo da Comunidade Metrô-Mangueira - "Retomar as obras";

a respeito do volume de recursos aplicados neste projeto pelo governo do ex-prefeito Eduardo Paes e, por sua vez, quanto o prefeito Marcelo Crivella pretende aplicar até a conclusão do projeto - "A obra tem valor de R\$ 10 milhões e foram executados pela gestão anterior em torno de 13\%";

aproveitamento do projeto original elaborado durante o governo do ex-prefeito Eduardo Paes e previsão de benefícios para a população com a implantação do Polo Automotivo da Mangueira, inclusive com a instalação de equipamentos de lazer está mantida? - "Todo o projeto licitado será aproveitado";

estabelecimentos comerciais a serem criados e critérios para sua distribuição aos comerciantes interessados - "Os benefícios serão o ordenamento daqueles comerciantes, com a padronização dos boxes, trazendo aquele comércio para a formalidade";

sobre a prioridade de ocupação para os comerciantes que já estavam estabelecidos no espaço à época da Comunidade Metrô-Mangueira e eventuais critérios para essa prioridade "Sim. Os comerciantes que lá estão foram cadastrados e serão realocados para o novo Polo";

outros possíveis planos de reforma urbana a serem realizados no governo do prefeito Marcelo Crivella - "Infelizmente não tenho como responder ao item 6"; 
viabilidade e interesse em realizar uma parceria público-privada para atender os moradores e comerciantes da Comunidade Metrô-Mangueira - "Para o Metrô-Mangueira não há previsão".

Constata-se um descaso político com os moradores e comerciantes da combalida Comunidade Metrô-Mangueira. As lacônicas respostas do subsecretário, talvez influenciadas pelo marasmo da gestão da atual Prefeitura, dão mostras de não estar disposta a assumir compromissos mais objetivos com a população de baixa renda e de que a situação dos moradores e dos comerciantes da comunidade vai continuar a mesma. Ressalte-se que alguns barracos e comércios foram reconstruídos pelos proprietários apesar do descaso da Prefeitura.

A afirmativa de que os projetos terão continuidade, apesar de apenas 13\% estarem construídos pelo governo anterior, significa que a mesma política de privilegiamento das empresas de obras públicas tende a continuar. De perspectiva mais favorável, apenas existe a condição de serem realocados no Polo Automotivo de Mangueira os comerciantes que foram cadastrados. Resta acompanhar se tal promessa será efetivamente cumprida.

\section{CONCLUSÃO}

Está caracterizado na atuação da Prefeitura da Cidade do Rio de Janeiro, com a condução do processo gentrificação e de remoções forçadas, que a sua preocupação principal era transformar o espaço ocupado pelos moradores da Comunidade Metrô-Mangueira em mais uma fonte de renda para o município e para as empresas que viessem a se apropriar dele. Não hesita em utilizar um discurso falacioso, de diagnosticar o espaço como área de risco, ficando bem distante da realidade, ou em usurpar a lei, não indenizando a população com o valor justo e adequado, a fim de que pudesse reiniciar a vida de maneira mais confortável, em respeito aos direitos humanos à cidadania.

Com este comportamento sistemático, a Prefeitura da Cidade do Rio de Janeiro deixa entrever, dentro do quadro de dificuldades estruturais por que passa o país, sua determinação no sentido de excluir essa parcela da população dos benefícios que a vida urbana possa the oferecer, pois não são preferencialmente destinados a ela.

A chegada à Prefeitura do governo Marcelo Crivella parece também não oferecer uma perspectiva favorável para a superação do descaso a que foram submetidos os moradores e comerciantes da Comunidade Metrô-Mangueira, haja vista a falta de previsibilidade mencionada pelo subsecretário de infraestrutura. 
Diante desse quadro esboçado pelo gestor público, um dos encarregados pelas obras públicas na cidade do Rio de Janeiro, fica a impressão de que os cariocas, cuja esperança de mudanças foi marcada pela eleição passada, trocaram a gentrificação do ex-prefeito Eduardo Paes pela inércia do atual prefeito Marcelo Crivella, que também não deixa de ser perniciosa para os interessados nos destinos da Comunidade Metrô-Mangueira.

Por fim, ressalte-se que as categorias trabalhadas ao logo do texto (políticas públicas de gentrificação e de remoções forcadas, direito à cidade, direito de resistência), demonstram que o caso da Comunidade Metrô-Mangueira é representativo da generalidade do que ocorreu e ainda vem ocorrendo no manejo do modelo de cidade capitalista no Rio de Janeiro.

\section{REFERÊNCIAS}

BELLO, Enzo. A cidadania na luta política dos movimentos sociais urbanos. Caxias do Sul: EDUCS, 2013.

Política, cidadania e direitos sociais: um contraponto entre os modelos clássicos e a trajetória da América Latina. 2007. 199 f. Dissertação (Mestrado em Ciências Jurídicas). Rio de Janeiro, Pontifícia Universidade Católica do Rio de Janeiro (PUC-Rio), 2007.

BERMAN, Marshall. Tudo que é sólido desmancha no ar: a aventura da modernidade. 3. ed. São Paulo: Cia das Letras, 2005.

BRASIL. Lei $n^{\circ} 10.257$, de 10 de julho de 2001. Regulamenta os arts. 182 e 183 da Constituição Federal, estabelece diretrizes gerais da política urbana e dá outras providências. Lex. Brasília, DF: [s.n.], 2001.

COSTA, Gilberto. Invisibilidade social é desafio para erradicar extrema pobreza. Agência Brasil. Disponível em: <http://www.fetecpr.org.br/invisibilidade-social-e-desafio-para-erradicarextrema-pobreza>. Acesso em: 11 jun. 2012.

COSTA, Pedro D'Angelo da; FIGUEIRA, Luiz Eduardo de Vasconcellos. Práticas de governo e direito à moradia: remoções na Favela Metrô-Mangueira. In: CONGRESSO DO CONSELHO NACIONAL DE PESQUISA E PÓS-GRADUAÇÃO EM DIREITO (CONPEDI), 25., 2016, Curitiba. Anais... Florianópolis: CONPEDI, 2016, p. 200-215.

DOUZINAS, Costa. Philosophy and resistance in the crisis. Cambridge: Polity Press, 2013.

FAULHABER, Lucas; AZEVEDO, Lena. SMH 2016: remoção no Rio de Janeiro Olímpico. Rio de Janeiro: Mórula, 2015.

GUARIENTO, Suellen. Luta da favela do Metrô: experiência de um processo em curso na cidade. Revista Intratextos, v. 6, n. 1, p. 109-124, 2015.

HALL, Stuart. A identidade cultural na pós-modernidade. 10. ed. Rio de Janeiro: DP\&A, 2005.

HARVEY, David. A brief history of neoliberalism. New York: Oxford Univ. Press, 2005. 
The right to the city. New Left Review, n. 53, p. 23-40, Sept./Oct. 2008.

A condição pós-moderna. Tradução de Adail Ubirajara Sobral; Maria Stela Gonçalves. 19. ed. São Paulo: Loyola, 2010.

Paris: capital da modernidade. Tradução de Magda Lopes. São Paulo: Boitempo, 2015.

HORKHEIMER, Max. Teoria Tradicional e Teoria Crítica. In: CIVITA, V. (ed.). Benjamin, Habermas, Horkheimer, Adorno: textos escolhidos. São Paulo: Abril, 1983, p. 125-162.

LEFEBVRE, Henry. O direito à cidade. São Paulo: Documento, 1969.

MANTELLI et al. (Orgs.). Megaeventos e violações dos Direitos Humanos no Rio de Janeiro. Dossiê do Comitê Popular da Copa e Olimpíadas do Rio de Janeiro, nov. 2015. Disponível em: <http://www.childrenwin.org/wp-content/uploads/2015/12/Dossie-Comit\%C3\% AARio2015_low.pdf>. Acesso em: 12 maio 2017.

MARICATO, Ermínia. A Copa do Mundo no Brasil: tsunami de capitais aprofunda a desigualdade urbana. In: JENNINGS, Andrew; ROLNIK, Raquel; LASSANCE, Antônio et al. Brasil em jogo: o que fica da Copa e das Olimpíadas. São Paulo: Boitempo; Carta Maior, 2014, p. 22.

MARIZ, Renata. Brasil terá ao menos 2,5 milhões de "novos pobres" até o fim do ano. O Globo. Disponível em: <https://oglobo.globo.com/brasil/brasil-tera-ao-menos-25-milhoes-de-novospobres-ate-fim-do-ano-20915254\#ixzz4k0JAdF1k>. Acesso em: 13 fev. 2017.

MEIRELES, Manuela de Carvalho. Tutela Coletiva em disputa: uma análise gramsciana do instituto. 2018. 160 f. Dissertação (Mestrado em Direito). Rio de Janeiro, Universidade do Estado do Rio de Janeiro, 2018.

MULATINHO, Juliana Pessoa. Neoliberalismo e neodesenvolvimentismo: Construção e desconstrução da cidadania no Brasil. Revista Direito \& Praxis, Rio de Janeiro, v. 8, n. 14, p. 198225, 2016.

OLIVEIRA, Daniela Ferreira. Qualidade de vida em habitação de interesse social: caso MetrôMangueira. 2015. 106 f. Dissertação (Mestrado em Engenharia Urbana) - Universidade Federal do Rio de Janeiro, Escola Politécnica, Programa de Engenharia Urbana, Rio de Janeiro, 2015.

RIBAS, Luiz Otávio; PAZZELO, Ricardo Prestes. Direito insurgente: (des) uso tático do direito. In: KASHIURA JR., Celso Naoto; AKAMINE JR., Oswaldo; MELO, Tarso. (Orgs.). Para a crítica do direito: reflexões sobre teorias e práticas jurídicas. São Paulo: Outras Expressões/editorial Dobra, 2015, p.147-166.

RIOONWATCH. A remoção lenta e sofrida da Favela Metrô-Mangueira. Disponível em: <http://rioonwatch.org.br/?p=3051>. Acesso em: 16 maio 2017(a).

A remoção sem fim: demolição, protesto e violência policial voltam à favela do metrô. 9 jan. 2014. Disponível em: <http://rioonwatch.org.br/?p=9995>. Acesso em: 13 maio 2017(b).

ROLNIK, Raquel. O que é cidade. 3. ed. São Paulo: Brasiliense, 2004.

SANTOS, Milton. Por uma outra globalização: do pensamento único à consciência universal. 5. ed. Rio de Janeiro: Record, 2001. 
SMITH, Neil. A gentrificação generalizada de uma anomalia local à "regeneração" urbana como estratégia urbana global. In: BIDOU-ZACHAIASEN, Catherine (Coord.). De volta à cidade: dos processos de gentrificação às políticas de revitalização dos centros urbanos. São Paulo: Annablume, 2006, p. 59-87.

VAINER, Carlos. Como serão nossas cidades após Copa e das Olimpíadas? In: JENNINGS, Andrew; ROLNIK, Raquel; LASSANCE, Antonio et al. Brasil em jogo: o que fica da Copa e das Olimpíadas? São Paulo: Boitempo; Carta Maior, 2014, p. 71-78.

Trabalho enviado em 19 de julho de 2017.

Aceito em 24 de julho de 2017. 